\title{
Study on the Current Patterns of Chinese Comedy Films
}

\author{
Yi Luo \\ Sichuan Conservatory of Music, Chengdu, Sichuan, 610500
}

\author{
Keywords: Current Patterns, Chinese Comedy Films, Development Trend
}

\begin{abstract}
Since the new century, with the rapid expansion of the film market, the audience looks forward to a variety of film creation, the film gradually become open and diverse forms. Comedy film concept of the market shift making the domestic comedy film creation to break through the limitations of the previous subjective large-scale cluster creation. Ten years of Chinese film has undergone tremendous changes, industrial policy guidance and expansion of market demand has brought unprecedented opportunities and vitality. It can be said that how to effectively promote and develop the characteristics of Chinese films on the basis of local experience directly affect the process of Chinese film industry. It is in this context, in recent years, the creation of domestic comedy film showing a vigorous development trend.
\end{abstract}

\section{Introduction}

The comic film creation in the new century shows a great contrast to the heat before and after the cold. In the beginning of the new century, comedy film creation is more silence, more movies are followed by the 90's "pan comedy film creation" situation. In 2006, Ning Hao director of the "crazy stone" to the dull comedy film creation has brought a recovery opportunity. Comedy film has a natural small cost advantage, the degree of dependence on the film industry is also low, and the local characteristics of the distinctive, and the reality of the formation of intertextuality, easy to cause the audience to resonate, is the output of the most cost-effective domestic film type. The next few years, the number of small and medium-sized comedy film rose sharply, almost every year nearly 20 comedy film release, comedy and love films, action films to form the domestic trend of the film. Many young directors have been put into comedy creation, a time to form a magnificent small and medium cost comedy tide, relying on comedy born type affinity, the film creator quickly and other types of grafting, making recent years of domestic comedy in the type of exploration made a certain Results. At the same time, the popular culture of pop culture and network culture directly affect the comedy film creation, in the comedy narrative performance as a unique "small tendency".

\section{The Types of Contemporary Chinese Drama Films}

Love film is the current domestic film in the important type of film. Love films tend to tend to male and female protagonist of the outcome of the reunion, and comedy film pursued by the perfect narrative spirit coincide, so love film and comedy piece of mutual integration into comedy creation common routines. After the new century, the domestic love comedy draws on the Hollywood city romantic love comedy, forming a more influential comedy type. The current love comedy has two main styles, one is warm and romantic light comedy style, such as "love call transfer", "love around", "peach blossom", "very perfect", "You Are the One" series, "slim gentleman" "Love the whole city", "love lover", "the mouse fell in love with the cat", "dragon and phoenix shop" and so on. The first type of film based on the city, mainly in the love story appropriate to join the comic elements, in order to easily joking way to interpret the younger generation of urban love, workplace life, while running through youth inspirations, fashion consumption and other elements, Showing a humorous comedy effect. After a class of love comedy is mostly hot and funny style, love story as a line of clues, as a series of exaggerated funny scenes, with postmodern comedy style features. These films tend to have compressed space and time, through the history of the postmodern features, the plot is empty, gimmicks endless, in exaggerated and enjoy the joking in the subversion and "spoof" 
happy. In fact, love comedy is not the first comedy film creation of the first, Feng Xiaogang early New Year comedy belongs to the love comedy, "no missing", "endless" and so are in the romance of the type of paradigm into the language humor A hypothetical comedy situation in the completion of the love story of the demands of the audience to get the imagination of love to meet.

Domestic black comedy is the bottom of the little people for the performance of the object, by the reality of social background to introduce crime, thriller elements, in the double line narrative show absurd plot. From the source point of view, this "black whirlwind" from the impact of Western films, "crazy stone" is a reference to the famous British director Ge Ridge in the "two big smoke", "stealing" style. Of course, in the process of localization and localization of black comedy, the original characteristics of the type have changed a lot. The elements of violence and crime are limited in the real environment of China, and the creator turns to the city the bottom of the struggle in order to survive and dignity desperately struggling little people, in a complex chaos, the authenticity of the real space to create a sense of absurdity. In general, these comedy plays are relatively high, reflecting a certain degree of comedy narrative ability, in the fictional plot hidden in the reality of allegory and reference, absurd tragic humor on the current unreasonable reality of the situation Mockery and rebellious criticism, revealing serious meanings under a variety of dense jokes. Crime, action, horror and other elements of the introduction, not only to meet the audience view of a wide range of expectations, but also to a certain extent make up for the current domestic film gangster film, criminal film lack of regret. But at the same time domestic black comedy creation is still in the imitation stage, although with non-linear multi-line narrative, coincidence plot and absurd comedy power, but failed to further reveal the form behind the author's attitude. The majority of follow the trend cannot help but flow in the form, did not form a real localization style.

The largest number of domestic comedy movies is undoubtedly the costume drama. The reason is called "farce", because these comedy is generally subversive-based, parody, spoof, collage in these movies are everywhere. "The world's second" and "full nine beauty" is an earlier to spoof the creation of costume comedy, especially in the "perfect nine beautiful" to small broad, made 47 million box office results, a large number of costume farce, "The Sui Dynasty visitors", "Panda heroes", "Royal Tattoo", "swordsman", "hee travel", "three laughs gifted wife", "knife laughed", "martial arts", "laughing rivers and lakes "... on the basis of the costume form, the deconstruction of the entertainment of the history, to the ancient irony of this way to the real society to refer to the depth of the digestion of the folk carnival, to a certain extent, to help the audience decompression The From the source, the costume farce comes from the nineties of last century popular Hong Kong nonsense costume comedy. However, the thoughtless comedy, represented by Stephen Chow's film, is "behind the performance of the characters in the language of the absurd words," the critics' criticism and deconstruction of the ideological authority, and on the other hand, Discourse system, with the mass culture of the code to consume as a commodity 'authority' to black humor way to re-win the irony and critical power. " However, in the current domestic costume farce, the narrator ridicule the object collective "face", from the representative of the authority of the "faint officer" series replaced by three kinds of people: unruly profiteers, chicken dog theft, bottom grass, social identity Of the "downgrade" makes the laughter in the real meaning of the appointment of the thinning, should bear the social criticism function disappeared, the audience can not correspond to complete their own cultural identity, the evaluation of such comedy relative to love comedy and Black comedy is low.

\section{Chinese Comedy Film Miniaturization Tendency}

Feng Xiaogang is a soft spot for the pieces of a soft spot, "Party B" by "dream day trip" formed a "collection of goods", on this basis, "Feng Xiaogang's film is actually arranged for the public an adult Children's game, that is, imitate the object upside down, become adult comedy imitation of children's game. " From the "endless" start, this game narrative gradually enlarged, enhanced entertainment and ornamental at the same time dismantling the tension of the traditional narrative, the audience expectations of the outcome of alienation, instead concerned in the game narrative show Of the comedy "essay" scripts. Since the new century, this trend continues, Feng Xiaogang 
often designed to let the protagonist to "talk about", even to suspend the narrative at the expense of the audience to appreciate this "language wonders" in his recent love comedy "You Are the One 2" This vivid narrative strategy is still largely used. Jiang Wen's "Let the bullets fly" will also comedy elements of the line, the plot, in the habit of the narrative of the audience there is a "can only be unspeakable" fun. Commodity taste is now a common feature of domestic comedy movies, but also the success of the mainland film box office important magic weapon, has penetrated into large and small comedy movies. However, the sketch, after all, is a small-capacity stage art, and the film is essentially different. The narrative of the film is a whole, and the excessive sophistication will destroy its integrity. When the "sketch" cannot be used as a "joke" for the narrative service of the film, it will hurt the development of comedy movies. Cohen brothers "blood labyrinth" is a tightly structured black suspense film, but after Zhang Yimou remake of the "three guns surprise", into a blunt comedy comedy elements of the portfolio, the film Zhao class class and two to the basic And character character characterization, the story of the development has nothing to do, lost the original tight narrative structure, reduced to a hodgepodge of small items. "You Are the One 2" is also a combination of small highlights, the lack of organic links between the various scripts, the audience questioned "there is no shape of the story." Narrative rupture is a problem of traditional Chinese martial arts films, but the prevalence of small product strategy, so that domestic comedy film creation is also frequent narrative rupture, resulting in the story of logic, character integrity of the integrity of the injury. At the same time, the young audience of the film, the rapid spread of the network culture, directly stimulated the film creator of the nerve, and further stimulate the small creation. Many small and medium cost comedy is the use of network vocabulary, hot network events to enhance the "laugh" fruit. "Network miniaturization" to expand the horizon of comedy creation, but the network culture turnover speed is extremely fast, over-reliance is easy to comedy film creation reduced to fast food, speed decay.

\section{Conclusion}

The current comedy film creation on the market is mostly due to the occasional gambling mentality, "reproducibility" is low. Whether it is with foreign comedy film production or compared with the domestic film tradition, the current comedy creation lack of brand quality, and the series of comedy creation is also no trace, although a small number of films made a sequel but the word of mouth is very different from the previous. A good film industry chain needs brand products long-term production, for the current domestic comedy film plagiarism, spoof, patchwork and other issues, by the "Thai" popular re-reconstruction of the audience comedy film confidence and expectations are placed in the majority Film workers and researchers in front of the important issues. In the context of the era of global competition, we need to further find the unique advantages of Chinese comedy movies, and strive to build a series of Chinese comedy series of films to achieve the scale of Chinese comedy film upgrades and sustainable development.

\section{Acknowledgements}

General Project of Sichuan Department of Education, Project No.: 14 SB0257

\section{References}

[1] Rao Shuguang, Xian Jia. The Structural Characteristics and Prospects of Contemporary Chinese Film Creation [J]. Journal of Zhejiang Institute of Communication Studies,2013 (01)

[2] Cai Jun. Talk about the film "man and then embarrassing way Thai Jong" comedy [J]. Film review. 2013 (02)

[3] Liu Shuo. China's film narrative in the transition period [J]. Contemporary film, 2012 (11)

[4] Chen Yu. Homemade comedy film casino [J]. Contemporary film, 2012 (07) 